\title{
Qualidade de Vida do Trabalhador da Saúde: Papel do Gestor no Contexto
}

\author{
Santiago, Alessandra; Martins, Marcia; Benevides, Ana Lucia; Mezzomo, Augusto Antonio \\ Instituto Central do Hospital das Clínicas — alessandra.santiago@hc.fm.usp.br
}

INTRODUÇÃO: a qualidade de vida do trabalhador da saúde é um dos focos de atuação da rede de humanização de um hospital público da cidade de São Paulo. Seu quadro de pessoal abrange aproximadamente 6000 colaboradores. o cotidiano de vida desses colaboradores requer uma atenção dos gestores tendo em vista não só a situação de estresse vivenciada por eles no ambiente hospitalar, mas também a sobrecarga emocional e social decorrentes da vida na cidade grande. Analisando este contexto a rede e humanização planejou um ciclo de palestras para a liderança com espaço para debates e os temas abordados eram pertinentes e de grande interesse dos colaboradores e liderança. Os temas escolhidos e desenvolvidos foram: "A Humanização com Foco na Saúde do Trabalhador, Arquitetura Hospitalar e Ambiência Interferência na Qualidade de Vida". "Projeto Cuidando de Quem Cuida" OBJETIVOS: Conscientizar a liderança sobre a importância da promoção da qualidade de vida do trabalhador da saúde no seu cotidiano de trabalho no hospital. Estimular a corresponsabilidade da liderança na garantia de um ambiente seguro e saudável para o desempenho das atividades do trabalhador da saúde..METODO: Planejamento e realização de ciclo de palestra sobre a qualidade de vida do trabalhador da saúde;Avaliação do ciclo e análise das críticas e sugestões dos líderes.Elaboração de planos de ação subsidiados pelas sugestões dos líderes.RESULTADOS:O ciclo de palestra atingiu o objetivo esperado como mostram os dados da avaliação: Relevância dos temas abordados: $92 \%$ dos participantes consideraram excelente e bom;86\% consideram que se aplica à sua realidade; $70 \%$ consideraram que houve equilíbrio entre a teoria e prática.Podemos observar a grande aceitação dos temas escolhidos, os dados apontam resistência da aplicação na prática. Foram apresentadas 114 sugestões que subsidiarão os planos de ação da rede junto às lideranças. CONCLUSAO: a maior parte dos programas desenvolvidos em hospitais de treinamento e capacitação do trabalhador da saúde, está voltada para a parte técnica de sua função e não relacionam com as condições de trabalho necessárias para um bom desempenho.Nos dias atuais já se observa uma maior preocupação dos gestores dos hospitais em relação à qualidade de vida do trabalhador e vários programas preventivos estão sendo desenvolvidos mas por outro lado nem sempre a liderança se compromete ou está envolvida.A rede de humanização pretende reforçar junto as lideranças a importância do seu envolvimento para garantia da promoção da saúde e satisfação do trabalhador resultando num melhor desempenho e na humanização do ambiente hospitalar. a maior parte dos programas desenvolvidos em hospitais de treinamento e capacitação do trabalhador da saúde, está voltada para a parte técnica de sua função e muitas vezes Nem sempre os hospitais em seus programas de treinamento e de capacitação abordam sobre as condições de trabalho necessárias para um bom desempenho do trabalhador em suas funções .Nos dias atuais já se observa uma maior preocupação dos gestores dos hospitais em relação à saúde do trabalhador e vários programas preventivos estão sendo desenvolvidos mas por outro lado nem sempre a liderança se compromete ou é envolvida neste processo.A rede de humanização pretende reforçar junto as lideranças a importância do seu envolvimento para garantia da promoção da saúde e satisfação do trabalhador resultando num melhor desempenho e na humanização do ambiente hospitalar.

Santiago, Alessandra; Martins, Marcia; Benevides, Ana Lucia; Mezzomo, Augusto Antonio. Qualidade de Vida do Trabalhador da Saúde: Papel do Gestor no Contexto. In: Anais do Congresso Internacional de Humanidades \& Humanização em Saúde [= Blucher Medical Proceedings, num.2, vol.1]. São Paulo: Editora Blucher, 2014.

ISSN 2357-7282

DOI 10.5151/medpro-cihhs-10625 